\title{
Anti-Inflammatory Effects of a Methanol Extract from the Marine Sponge Geodia cydonium on the Human Breast Cancer MCF-7 Cell Line
}

\author{
Susan Costantini, ${ }^{1}$ Giovanna Romano, ${ }^{2}$ Fabiola Rusolo, ${ }^{1}$ \\ Francesca Capone, ${ }^{1}$ Eliana Guerriero, ${ }^{1}$ Giovanni Colonna, ${ }^{3}$ Adrianna Ianora, ${ }^{2}$ \\ Gennaro Ciliberto, ${ }^{4}$ and Maria Costantini ${ }^{5}$ \\ ${ }^{1}$ CROM, Istituto Nazionale Tumori "Fondazione G. Pascale”, IRCCS, 80131 Napoli, Italy \\ ${ }^{2}$ Department of Integrative Marine Ecology, Stazione Zoologica Anton Dohrn, Villa Comunale, 80121 Napoli, Italy \\ ${ }^{3}$ Servizio di Informatica Medica, Azienda Ospedaliera Universitaria, Seconda Università di Napoli, 80138 Napoli, Italy \\ ${ }^{4}$ Direzione Scientifica, Istituto Nazionale Tumori "Fondazione G. Pascale", IRCCS, 80131 Napoli, Italy \\ ${ }^{5}$ Department of Biology and Evolution of Marine Organisms, Stazione Zoologica Anton Dohrn, Villa Comunale, 80121 Napoli, Italy
}

Correspondence should be addressed to Maria Costantini; maria.costantini@szn.it

Received 16 November 2014; Revised 19 January 2015; Accepted 20 January 2015

Academic Editor: Francesco Cecconi

Copyright ( $(2015$ Susan Costantini et al. This is an open access article distributed under the Creative Commons Attribution License, which permits unrestricted use, distribution, and reproduction in any medium, provided the original work is properly cited.

\begin{abstract}
Many research groups are working to find new possible anti-inflammatory molecules, and marine sponges represent a rich source of biologically active compounds with pharmacological applications. In the present study, we tested different concentrations of the methanol extract from the marine sponge, Geodia cydonium, on normal human breast epithelial cells (MCF-10A) and human breast cancer cells (MCF-7). Our results show that this extract has no cytotoxic effects on both cell lines whereas it induces a decrease in levels of VEGF and five proinflammatory cytokines (CCL2, CXCL8, CXCL10, IFN- $\gamma$, and TNF- $\alpha$ ) only in MCF-7 cells in a dosedependent manner, thereby indicating an anti-inflammatory effect. Moreover, interactomic analysis suggests that all six cytokines are involved in a network and are connected with some HUB nodes such as NF-kB subunits and ESR1 (estrogen receptor 1). We also report a decrease in the expression of two NFKB1 and c-Rel subunits by RT-qPCR experiments only in MCF-7 cells after extract treatment, confirming NF-kB inactivation. These data highlight the potential of G. cydonium for future drug discovery against major diseases, such as breast cancer.
\end{abstract}

\section{Introduction}

Inflammation is a physiological process in response to acute tissue damage resulting from physical and ischemic injury, infection, exposure to toxins, chemical irritation, and/or other types of trauma. Many authors have suggested a correlation between chronic inflammation and cancer [1]. In fact, while inflammatory diseases increase the risk of developing many types of cancer, some nonsteroidal anti-inflammatory drugs reduce this risk for certain cancers (e.g., breast cancer) [2]. Interestingly, inflammation is involved in all three stages of tumor development, initiation, progression, and metastasis, where cytokines, chemokines, and growth factors play an important role in their evolution [3]. These are proteins that are expressed before and during the inflammatory process and play a key role during various disease stages so as to be considered as specific cancer markers as well as markers for various stages of the disease [2]. In general, the cytokinome is defined as the totality of these proteins and their interactions in and around cells [4]. Understanding the complex interaction network of cytokines in cancer patients should be very useful both to follow the evolution of cancer from its first steps and to define therapeutic strategies using innovative systems biology approaches. Several research groups are working to find new possible anti-inflammatory molecules [5]. Indeed, our laboratory has also recently evaluated the putative anti-inflammatory effects of different molecules such as sodium selenite, lipoic acid, and caffeic acid on cancer cell 
lines $[6,7]$ as well as of natural extracts from pomegranate (Punica granatum L.) seed oil [8] and Juniperus oxycedrus ssp. oxycedrus berries [9].

The marine environment, with its impressive biodiversity, is a rich natural resource of many biologically active compounds such as antioxidants, polyunsaturated fatty acids (PUFAs), sterols, proteins, polysaccharides, and pigments. In fact, many marine organisms live in complex habitats and are exposed to extreme conditions and produce a variety of biologically active secondary metabolites, which often have no terrestrial counterparts. Sponges seem to be particularly rich sources of bioactive compounds which show antiviral [10], antibacterial [11], and anti-inflammatory activities [1215]. They are also promising candidates as anticancer drugs considering that 3 of the 4 commercial anticancer drugs available have been derived from marine sponges, including Ara-C from the marine sponge Tectitethya crypta [16] that is currently used in the routine treatment of patients with lymphoma, Halaven (eribulin) from the sponge Halichondria okadai used for the treatment of breast cancer [17], and Yondelis from the marine tunicate Ecteinascidia turbinata for the treatment of soft tissue carcinoma [18]. For example, several anti-inflammatory metabolites have been isolated from sponges belonging to the class of the Demospongiae, including cavernolide from Fasciospongia cavernosa [19], contignasterol from Petrosia contignata [20], and cyclolinteinone from Cacospongia linteiformis [21]. Therefore, the purpose of the present study was to investigate the potential effects of a methanol extract from the marine demosponge, Geodia cydonium, which has not been studied previously for drug discovery, on normal human mammary epithelial cells (MCF-10A) and cells of human breast cancer (MCF-7).

\section{Materials and Methods}

2.1. Sample Collection and Preparation of the Methanol Extract. The marine sponge G. cydonium (Porifera, Demospongiae, Astrophorida, Geodidae) was sampled in the "Parco Sommerso di Baia" (Gulf of Naples, Italy). The sample was collected in October 2013 at a depth of 20 metres. Individual specimens were placed separately into plastic bags and kept in seawater basins of the Marine Resources for Research Service at the Stazione Zoologica Anton Dohrn of Naples at a temperature of $15-20^{\circ} \mathrm{C}$ for one month.

Sponges were cut into small pieces and $10 \mathrm{~g}$ of tissue was ground into liquid nitrogen and then soaked in $200 \mathrm{~mL}$ of methanol for 2 hours under stirring. The solvent was removed and filtered through Whatman filter paper No. 1; the sponge tissue was squeezed in cheesecloth. The solvent was evaporated at low pressure using a rotavapor (Büchi Rotavapor R114) at $40^{\circ} \mathrm{C}$ and the residual aqueous extract was partitioned three times against ethyl acetate $(2: 1 \mathrm{v} / \mathrm{v})$. To accelerate the phase separation, we centrifuged the extract at $2750 \mathrm{rcf}$ for 10 minutes at $4^{\circ} \mathrm{C}$ and the organic phase was collected. The organic phase of various preparations was pooled and treated with ammonium sulfate to remove any aqueous residues. Nonpolar components and phenolic molecules were separated by this extraction procedure [22]. The final extract was dried and stored at $-20^{\circ} \mathrm{C}$ until use.

2.2. Cell Culture. MCF-7 human breast cancer cells and MCF-10A normal human breast epithelial cells were cultured and expanded at $37^{\circ} \mathrm{C}$ in a humidified atmosphere of $5 \% \mathrm{CO}_{2}$ in DMEM culture medium (Dulbecco's Modified Eagle's Medium, Lonza, Verviers, Belgium), supplemented with FBS (Invitrogen, Camarillo, CA, USA) at 10\%, penicillin/streptomycin $1 \times$ (Euroclone, Devon, UK), and Glutamax 1× (Invitrogen). Moreover, in the case of MCF-10A the DMEM was supplemented also with human insulin $(10 \mu \mathrm{g} / \mathrm{mL})$, epidermal growth factor $(20 \mathrm{ng} / \mathrm{mL})$, and hydrocortisone $(0.5 \mu \mathrm{g} / \mathrm{mL})$ according to the procedure reported in [23].

2.3. Colorimetric Assay with Sulforhodamine B. Cell proliferation was assessed in the presence and absence of the methanol extract from G. cydonium by colorimetric assay with sulforhodamine B (SRB, Sigma Aldrich). The cells $(3.5 \times$ $10^{-4}-4 \times 10^{-4}$ ) were seeded in 96-multiwell plates in $200 \mu \mathrm{L}$ of culture medium and left to grow for $24 \mathrm{~h}$ at $37^{\circ} \mathrm{C}$ to allow adhesion. Cells were then treated with varying concentrations of the extract: $2 \mu \mathrm{g}, 50 \mu \mathrm{g}$, and $200 \mu \mathrm{g}$ and incubated for $24 \mathrm{~h}$. These concentrations were selected based on previous results on the effect of a methanol extract of this sponge on embryonic development in the sea urchin Paracentrotus lividus.

Dissolution of the extract was improved with $100 \mathrm{mM}$ dimethyl sulfoxide (DMSO, Sigma Aldrich). From this stock solution, dilutions were made to obtain the different amounts of extracts with a final concentration of $0.05 \%$ DMSO. Control cultured cells were incubated with the same volume of the solvent. Cells were fixed by adding $10 \%$ trichloroacetic acid (Sigma Aldrich) for at least $1 \mathrm{~h}$ at $4^{\circ} \mathrm{C}$. Subsequently, cells were washed with distilled water and air-dried. SRB $(100 \mu \mathrm{L})$ was added to each well and the plate was incubated for $30 \mathrm{~min}$ at room temperature in the dark. To remove excess dye, cells were washed with $1 \%$ acetic acid. The number of viable cells was directly proportional to the protein bounddye formation which was then solubilized with $100 \mu \mathrm{L}$ of $10 \mathrm{mM}$ Tris base solution $\mathrm{pH} 10.5$, shaking the plates for at least $15 \mathrm{~min}$ on an orbital shaker to homogenize the dye solution. Optical density measurements were performed by using an automated 96-well plate reader (Microplate Reader, Bio-Rad, Hercules, CA, USA) at $540 \mathrm{~nm}$. All experiments were performed in triplicate and were repeated for three times. Cellular viability was estimated as \% compared to untreated cells.

2.4. Bio-Plex Assay. Levels of cytokines, chemokines, and growth factors were evaluated at the same time with the BioPlex assay. The multiplex biometric ELISA-based immunoassay, containing dyed microspheres conjugated with a monoclonal antibody highly specific for a target protein, was used, according to the manufacturer's instructions (Bio-Plex Bio$\mathrm{Rad}$ ), to evaluate the levels of different cytokines by Human Cytokine 27-Plex in MCF-10A and MCF-7 supernatants after 
treatment with increasing concentrations of sponge extract. In particular, the following cytokines were evaluated: IL-1 $\beta$, IL-1ra, IL-2, IL-4, IL-5, IL-6, IL-7, CCL2, CCL11, CXCL10, CXCL8, IFN- $\gamma$, IL-9, IL-10, IL-12 (p70), IL-13, IL-15, IL-17, basic FGF, G-CSF, GM-CSF, MIP- $1 \alpha$, MIP- $1 \beta$, PDGF- $\beta \beta$, RANTES, TNF- $\alpha$, and VEGF. Protein levels were determined using a Bio-Plex array reader (Luminex, Austin, TX, USA) that quantifies multiplex immunoassays in a 96-well format with very small fluid volumes. The analyte level was calculated using a standard curve, with software provided by the manufacturer (Bio-Plex Manager Software).

2.5. Bioinformatics Analysis. The expression levels of cytokines evaluated in MCF-10A and MCF-7 supernatants were compared by $t$-test. Values of $P<0.05$ were considered to be statistically significant. The statistical program Prism 4 (GraphPad Software, San Diego, CA, USA) was used. The PANTHER (Protein ANalysis THrough Evolutionary Relationships) Classification System was designed to classify proteins according to their biological processes [24] as well as the metabolic pathways in which they are involved. Moreover, a network analysis was performed between the most significant proteins by ingenuity pathway analysis (IPA).

2.6. RNA Preparation and Reverse Transcription-qPCR (RT$q P C R)$ Analysis. Total RNA was extracted from MCF-7 cells that were either untreated (control) or exposed to increasing concentrations of sponge extract $(2 \mu \mathrm{g}, 50 \mu \mathrm{g}$, and $200 \mu \mathrm{g})$ using the RNAeasy Mini Kit (Qiagen Inc., Valencia, CA, USA) according to the manufacturer's instructions. The extracted RNA was dissolved in diethylpyrocarbonate treated water, and its concentration and purity were assessed by measurement of optical density at 260/280 nm. RNA samples were quantified using a NanoDrop 2000 spectrophotometer (Thermo Scientific, Wilmington, DE). Two micrograms of total RNA of each sample was reverse-transcribed with SuperScript VILO cDNA Synthesis Kit (Life TechnologiesInvitrogen, Carlsbad, CA, USA) according to the manufacturer's instructions and subsequently diluted with nucleasefree water (Life Technologies-Ambion).

Sequences for mRNAs from the nucleotide data bank (National Center for Biotechnology Information, USA) were used to design primer pairs for RT-qPCR (Primer Express, Applied Biosystems, CA, USA). Oligonucleotides were obtained from Sigma Aldrich. The primer sequences of $5 \mathrm{NF}-\kappa \mathrm{B}$ subunits' mRNAs are provided in Table 1 . An appropriate region of $18 \mathrm{~S}$ rRNA was used as control. RTqPCR assays were run on a Step-One Real Time PCR System (Applied Biosystems). $2 \mu \mathrm{L}$ of cDNA was amplified in a total volume of $25 \mu \mathrm{L}$ containing $2 \mathrm{X}$ SYBR Green PCR Master Mix (Applied Biosystems) and $300 \mathrm{nM}$ of forward and reverse primers. The thermal cycling conditions were as follows: $5 \mathrm{~min}$ of denaturation at $95^{\circ} \mathrm{C}$ followed by 44 cycles of a two-step program (denaturation at $95^{\circ} \mathrm{C}$ for $30 \mathrm{sec}$ and annealing/extension at $60^{\circ} \mathrm{C}$ for $1 \mathrm{~min}$ ). For each target, the primer sequences and the melting temperature are reported in Table 1. Dilutions of standards and test samples were run in duplicate. Each reaction was repeated at least
TABLE 1: Parameters for RT-qPCR analysis.

\begin{tabular}{lcl}
\hline Gene & Tm $\left[{ }^{\circ} \mathrm{C}\right]$ & Sequence $\left(5^{\prime} \rightarrow 3^{\prime}\right)$ \\
\hline NFKB1 & 59 & $\begin{array}{l}\text { CCTCTGTGTTTGTCCAGCT }(19) \\
\text { CCGAAAAATTGGGCATGAGC }(20)\end{array}$ \\
\hline NFKB2 & 58 & $\begin{array}{l}\text { GCTTCTCTGCCTTCCTTAG }(19) \\
\text { CACAGAGCCTGCTGTCTTG }(19)\end{array}$ \\
\hline RELA & 58 & $\begin{array}{l}\text { CACGAGCTTGTAGGAAAGG }(19) \\
\text { GCGCTGACTGATAGCCTG }(18)\end{array}$ \\
\hline RELB & 60 & $\begin{array}{l}\text { TGCTTCGGTCTGGGCCAG }(18) \\
\text { CAATTCATCTGTGCTCCTGG }(20)\end{array}$ \\
\hline C-Rel & 60 & $\begin{array}{l}\text { TCCTGACTGACTGACTGCG }(19) \\
\text { CTAAAACGCATTCCCCTCTG }(20)\end{array}$ \\
\hline 18 S & 60 & $\begin{array}{l}\text { CTGCCCTATCAACTTTCGTG }(20) \\
\text { GTAGTTTCTCAGGCTCCCTCTC }(22)\end{array}$ \\
\hline
\end{tabular}

three times. Expression levels of each target gene in MCF7 cells treated with different concentrations of the sponge extract were compared with those in untreated cells using the REST tool (Relative Expression Software Tool, Weihenstephan, Germany) [25]. The REST mathematical model is based on the correction for exact PCR efficiencies and the mean crossing point deviation between sample group(s) and control group(s). Subsequently the expression ratio results of the investigated transcripts are tested for significance by a Pair Wise Fixed Reallocation Randomisation Test (c) and plotted using standard error (SE) estimation via a complex Taylor algorithm (http://www.gene-quantification.de/rest.html). Data were normalized using the $18 \mathrm{~S}$ rRNA as housekeeping gene already used in our recent paper [26]. A 1 x-fold expression level was chosen as the threshold for significance of target genes.

\section{Results and Discussion}

3.1. Preparation and Viability Assay of the Methanol Extract. Sponges, due to the enormous diversity of associated microorganism communities, have always been considered an explicit source of pharmaceutical products. Our recent results showed that a diverse assemblage of bacteria resided in the marine sponge G. cydonium [27], including Pseudoalteromonas spp. that is reported to produce prodigiosin, a wellknown tripyrrolic red pigment with immunosuppressive and anticancer activities, mainly in human breast cancer [28]. However, to our knowledge, this is the first study testing the biological activity of extracts of this sponge.

A methanol extract of G. cydonium was prepared as reported for other marine sponges $[14,15]$. To identify the $\mathrm{IC}_{50}$ concentration, corresponding to the extract amount that causes $50 \%$ inhibition of cell growth, the cell viability of MCF$10 \mathrm{~A}$ and MCF-7 was determined after $24 \mathrm{~h}$ stimulation with sponge extract by colorimetric assay with sulforhodamine B (Figure 1). We chose this incubation time because it has already been used in previous studies $[14,15]$. Moreover, we tested the effect of methanol alone on two cell lines verifying that cell viability remained equal to $100 \%$. Therefore, the cellular viability of untreated cells was used as control. 


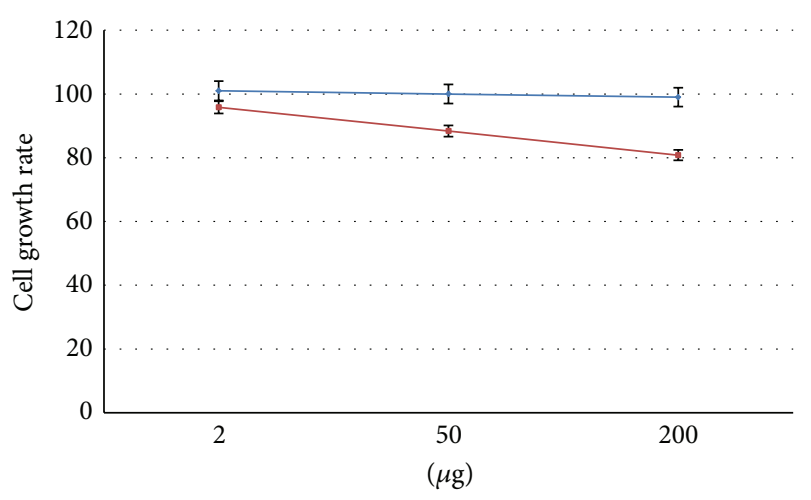

FIgURE 1: Cell growth rate after $24 \mathrm{~h}$ of treatment with different amount of sponge extracts in normal human breast epithelial cells, MCF-10A (blue), and human breast cancer cells, MCF-7 (red).

After $24 \mathrm{~h}$ of incubation, MCF-10A and MCF-7 cells retained a relatively constant viability with increasing concentrations of sponge extract, as demonstrated by the overlapping of growth curves in Figure 1. This suggests that our sponge extract had no antiproliferative or cytotoxic activities compared to other methanol extracts [14]. Interestingly, marine sponges of the genus Geodia (Demospongiae class, Tetractinellida order, Geodidae family) have been poorly explored for their chemical and biologically active components. Studies on the Mediterranean giant siliceous sponge Geodia gigas have led to the isolation of herbipoline (a biogenic amine) [29] and several steroidal ketones [30]. A series of cholestane derivatives have been isolated from another species, G. megastrella [31], and crude extracts of $G$. corticostylifera from the Brazilian coast have been reported as having antibacterial, antifungal, cytotoxic, haemolytic, and neurotoxic activities [32]. Some cyclic peptides geodiamolides A, B, H, and I were isolated from G. corticostylifera and their antiproliferative effects were demonstrated against sea urchin eggs and human breast cancer cell lines T47D and MCF7 by disorganizing actin filaments of these cells [33]. Furthermore, sponge depsipeptide, geodiamolide $\mathrm{H}$, from G. corticostylifera increased gap junction length in hepatocarcinoma cells, affecting mainly the delivery pathway of connexin 43 that is membrane proteins that form gap junction channels between adjacent cells [34].

3.2. Evaluation of Cytokine Levels. Since some studies have reported that methanol extracts from marine sponges show anti-inflammatory effects $[14,15]$, we evaluated the concentrations of 27 cytokines (expressed in $\mathrm{pg} / \mathrm{mL}$ ) in MCF$10 \mathrm{~A}$ and MCF-7 supernatants after treatment with G. cydonium sponge extract by multiplex biometric ELISA-based immunoassay. This simultaneous quantitative determination of a large cytokine panel enables us to correctly report ratios and dynamics between highly and poorly represented molecules. It represents an accurate, simple, specific, noninvasive, reproducible, and inexpensive method [6-8].

Results were compared with untreated cells used as controls. Experiments revealed that levels of VEGF and five proinflammatory cytokines (CXCL8, CXCL10, IFN- $\gamma$, CCL2, and TNF- $\alpha$ ) decreased in a dose-dependent manner with increasing levels of sponge extract in breast cancer MCF-7 cells (Figure 2) but not in healthy breast MCF-10A cells. Some studies have already demonstrated that CXCL8 and VEGF promoters contain different recognition sites for nuclear factor- (NF-) kappa B [35]. For example, CCL2 expression is activated by NF- $\kappa \mathrm{B}$ [36], TNF- $\alpha$ induces the activation of antiapoptotic transcription factor NF- $\kappa \mathrm{B}$ [37], and IFN$\gamma$ requires NF- $\kappa \mathrm{B}$ to induce expression of the CXCL10 gene [38]. These data suggest a specific anti-inflammatory effect of the sponge extract on cancer cells.

Anti-inflammatory effects have already been reported in marine sponges, including cavernolide from Fasciospongia cavernosa [19], contignasterol from Petrosia contignata [20], and cyclolinteinone from Cacospongia linteiformis [21]. These effects can be explained by the inhibition of enzymatic activities such as inhibition of inducible nitric oxide synthase (iNOS), cyclooxygenase-2 (COX-2) gene expression, and plasma exudation in vivo in response to ovalbumin and prostaglandin E2. Another compound halipeptin A was isolated from the marine sponge Haliclona sp., which has shown anti-inflammatory activity on mouse paw edema assay [39]. This metabolite seems to be more potent compared to standard anti-inflammatory drugs like indomethacin and naproxen for anti-inflammatory effects. Another metabolite petrosaspongiolide $\mathrm{M}$, isolated from the Caledonian marine sponge Petrosaspongia nigra, is a potent inhibitor in vivo and in vitro of phospholipase A2 (PLA2), demonstrating anti-inflammatory activity in models of acute and chronic inflammation [40].

However, there are few reports of sponge-derived compounds acting on specific cytokines. For example, barettin isolated from the marine sponge Geodia barretti was able to inhibit the secretion of two proinflammatory cytokines, IL-1 $\beta$ and TNF $\alpha$, from LPS-stimulated THP-1 cells, and the combination of its anti-inflammatory and antioxidant activities suggests that this compound could have an atheroprotective effect [41]. Moreover, Pfeifer et al. (1992) [42] identified a tumor necrosis-like factor in the sponge G. cydonium, an endotoxin that mediates necrosis formation in xenografts.

Our study provides a complete evaluation of the antiinflammatory effects of a methanol extract from the marine sponge G. cydonium, using a cytokinome approach where the cytokinome is defined as the totality of the cytokines and their interactions in and around biological cells as in [4]. Understanding the complex interaction network of cytokines should be very useful both to follow the evolution of cancer from its early steps and to define innovative therapeutic strategies by using systems biology approaches $[2$, 4]. However, a correct and comprehensive understanding of cytokine functions can be obtained only from simultaneous and coherent measurements of the serum concentrations of cytokines. This point raises the inherent difficulty of a simultaneous measurement of the cytokine concentrations to obtain correct internal ratios among the various molecules present in the same biological fluid or cellular supernatants due to the often large difference in concentrations spanning several orders of magnitude. At present, it is possible to 

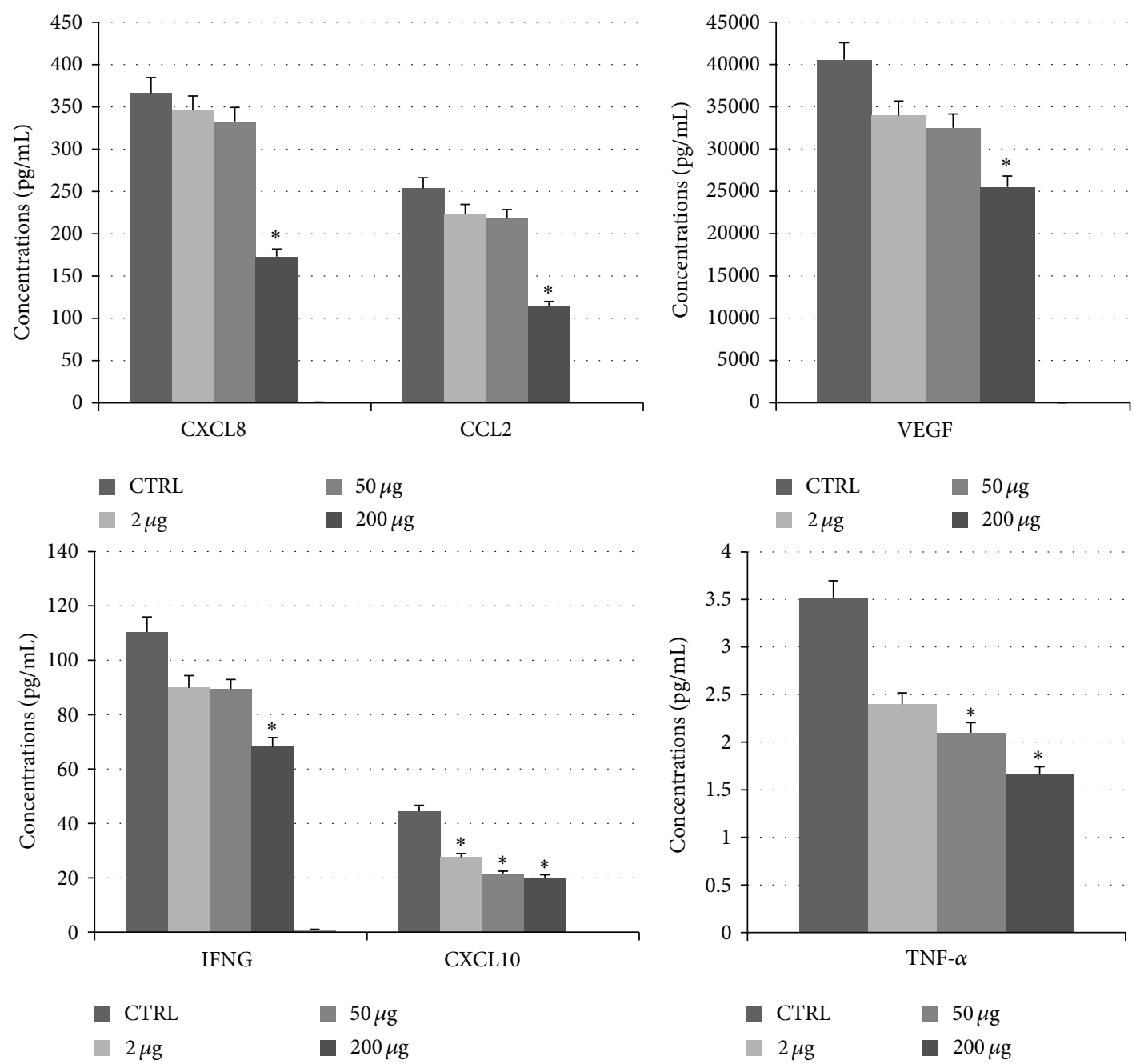

FIGURE 2: Statistically significant cytokine levels (expressed in pg/mL) evaluated in MCF-7 cells before and after treatment with different concentrations of sponge extract. Asterisks $*$ indicate the statistically significant differences between levels of untreated (used as controls and indicated with CTRL) and treated cells with $P<0.05$ using the $t$-test. In the legend, we report the meaning of the bars by using different colors for untreated cells (CTRL) and three different treatments. In detail, we report CXCL8 (C-X-C motif ligand 8), CCL2 (C-C motif ligand 2), VEGF (vascular endothelial growth factor), IFNG (interferon gamma), CXCL10 (C-X-C motif ligand 10), and TNF- $\alpha$ (tumor necrosis factor alpha).

effectively characterize cytokine levels only using a broadspectrum bead based multiplex immunoassay that was used in [4] and the present study.

\subsection{Functional and Network Analysis. To verify if these} proteins are correlated with one another through NF- $\kappa \mathrm{B}$, we performed a functional analysis on CCL2, CXCL8, CXCL10, IFN- $\gamma$, TNF- $\alpha$, and VEGF using the PANTHER tool [24] and then conducted a network study by ingenuity pathway analysis (IPA). Figure 3 shows that these six proteins are involved in 7 metabolic pathways: CCL2, CXCL8, CXCL10, and IFN- $\gamma$ in the inflammation signaling pathway mediated by chemokines and cytokines, VEGF in angiogenesis and the VEGF signaling pathway, TNF- $\alpha$ in apoptosis and the Wnt signaling pathways, CXCL8 in the interleukin signaling pathway, and IFN- $\gamma$ in the interferon-gamma signaling pathway.
Moreover, interactomic analysis shows that all of the six analyzed significant cytokines are involved in a network named "Cellular Movement, Immune Cell Trafficking, Hematological System Development and Function" on the basis of associated functions and data mining from experimental studies reported in the literature (Figure 4). This network reveals that these proteins are connected with some HUB nodes such as NF- $\kappa \mathrm{B}$ subunits (NF $\kappa \mathrm{B}$ complex and RELA) and ESR1 (estrogen receptor 1), which is a commonly used clinical breast cancer marker [43]. More specifically, (i) CCL2, CXCL8, CXCL10, IFN- $\gamma$, TNF- $\alpha$, and VEGF are connected with $\mathrm{NF}-\kappa \mathrm{B}$ subunits (NF $\kappa \mathrm{B}$ complex and RELA) and (ii) CCL2, CXCL8, TNF- $\alpha$, and VEGF with ESR1.

Therefore, our interactomic studies confirmed that these six significant cytokines were mutually interconnected by the $\mathrm{NF}-\kappa \mathrm{B}$ complex and suggested that a decrease in the levels 


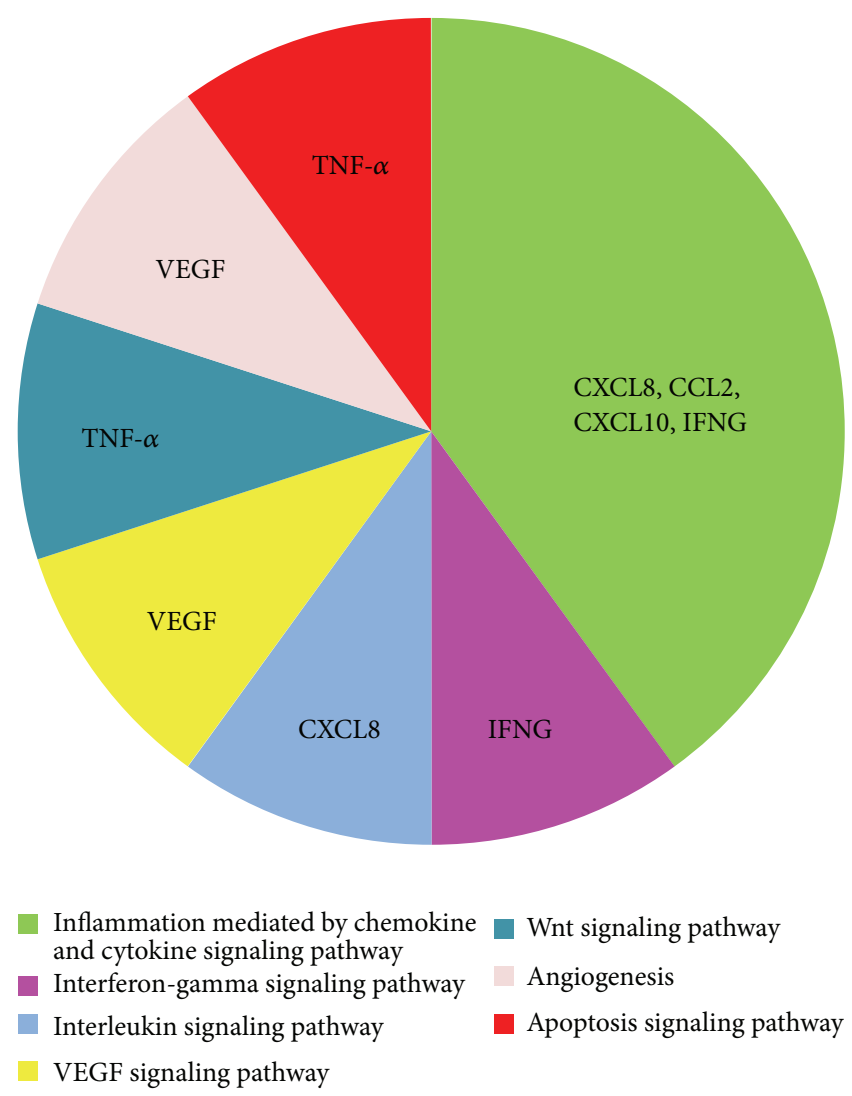

FIGURE 3: PANTHER pathway analysis in which we show the pathways related to the following six significant proteins: CXCL8 (C-X-C motif ligand 8), CCL2 (C-C motif ligand 2), VEGF (vascular endothelial growth factor), IFNG (interferon gamma), CXCL10 (C-X-C motif ligand $10)$, and TNF- $\alpha$ (tumor necrosis factor alpha).

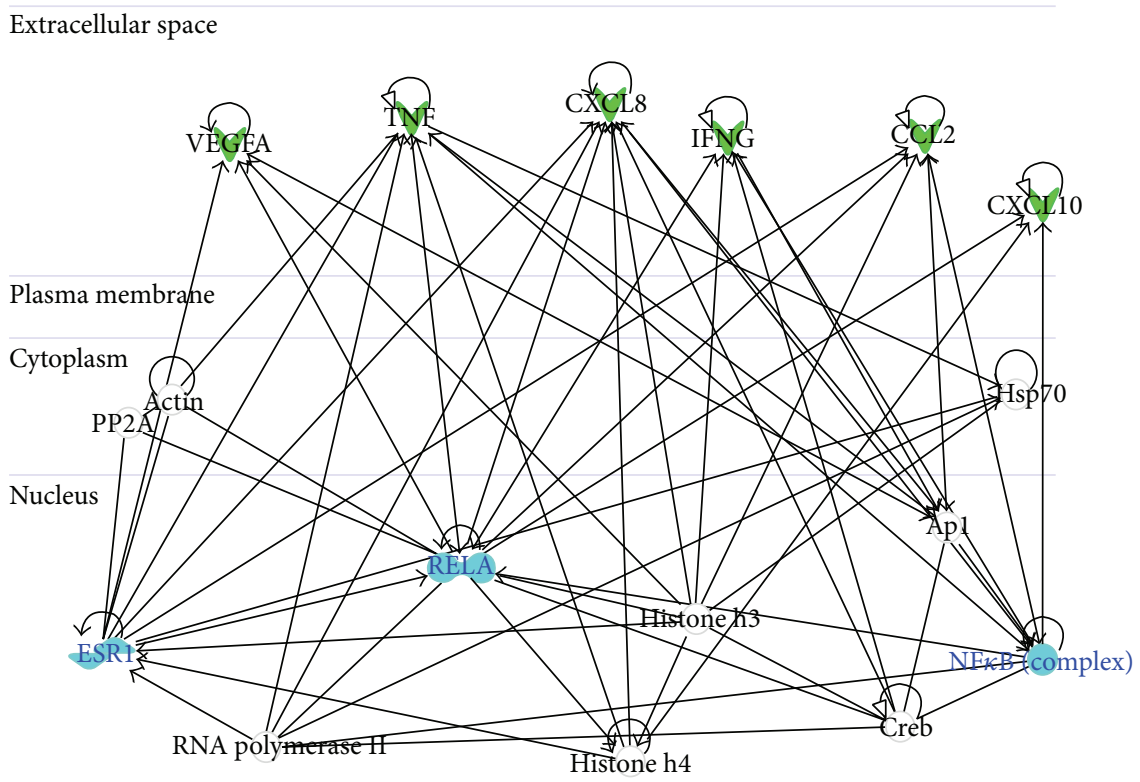

FIGURE 4: Interactomic analysis by ingenuity pathway analysis (IPA) of significant molecules. The interactome shows the close functional association between significant cytokines (indicated with green symbols) as well as the paths in which other functionally relevant molecules are also involved (indicated with white symbols). In detail, the cytokines reported are CXCL8 (C-X-C motif ligand 8), CCL2 (C-C motif ligand 2), VEGF (vascular endothelial growth factor), IFNG (interferon gamma), CXCL10 (C-X-C motif ligand 10), and TNF (tumor necrosis factor alpha). Moreover, three HUB nodes such as ESR1 (estrogen receptor 1), NF- $\kappa$ B (nuclear factor kappa B), and RELA (v-rel avian reticuloendotheliosis viral oncogene homolog A) subunits are indicated by cyan symbols. 
of these cytokines can inhibit the activation of NF- $\kappa \mathrm{B}$ by blocking tumor growth.

3.4. Expression Levels of NF- $\kappa B$ Subunits in MCF-7 Cells. It is known that the NF- $\kappa \mathrm{B}$ family shares a Rel homology domain in their $\mathrm{N}$-terminus. In particular, a subfamily of $\mathrm{NF}-\kappa \mathrm{B}$ proteins, including RELA, RELB, and c-Rel, has a transactivation domain in their $\mathrm{C}$-terminal regions. On the other hand, NFKB1 and NFKB2 proteins are synthesized as large precursors (p105 and p100), which are processed to generate the mature NF- $\kappa \mathrm{B}$ subunits (p50 and p52), respectively [44].

Therefore, to verify if NF- $\kappa \mathrm{B}$ was modulated by the sponge extract, the gene expression levels of the five NF$\kappa \mathrm{B}$ subunits, NFKB1, NFKB2, RELA, RELB, and c-Rel, in MCF-7 cells, treated with increasing concentrations $(2 \mu \mathrm{g}$, $50 \mu \mathrm{g}$, and $200 \mu \mathrm{g}$ ) of sponge extract, were evaluated by RTqPCR compared to those in untreated cells (Table 1). No significant changes in expression levels were observed for NFKB2, RELA, and RELB, whereas the two genes, NFKB1 and c-Rel, showed a statistically significant downregulation after treatment with sponge extract (Figure 5), thus confirming the downregulation of NF- $\kappa \mathrm{B}$. We are currently performing Western blot analysis to validate these results by the same protocol recently used in our group [45]. Preliminary results indicate no significant changes for RELA expression and a significant downregulation for NFKB1 in MCF-7 cells after treatment with $200 \mu \mathrm{g}$ of sponge extract compared to those in untreated cells (see Figure 1S in Supplementary Material available online at http://dx.doi.org/10.1155/2015/204975).

\section{Conclusions}

Cell response to stress includes a wide range of molecular processes that are activated through the modulation of signaling pathways that lead to repair, adaption, or cell death. Moreover, stress may induce a prolonged inflammation leading to several pathological conditions, which include cancer [3]. For this reason, we are working to discover novel antiinflammatory molecules [6-8].

In the past decades, several studies have shown that marine sponges contain compounds with anti-inflammatory activities $[14,15]$. Our results show that $G$. cydonium sponge extract (i) does not have a cytotoxic effect on both MCF$10 \mathrm{~A}$ and MCF-7 cell lines, (ii) induces a decrease in VEGF levels and of five proinflammatory cytokines (CCL2, CXCL8, CXCL10, IFN- $\gamma$, and TNF- $\alpha$ ) in a dose-dependent manner only in MCF-7 cells, and (iii) induces the downregulation of two NF- $\kappa$ B subunits, NFKB1 and c-Rel.

In conclusion, our findings reveal for the first time that a methanol extract from the marine sponge G. cydonium had no antiproliferative or cytotoxic activities but antiinflammatory effects by cytokinome approach on the human breast cancer MCF-7 cell line.

Studies are currently underway to chemically characterize the compounds produced by G. cydonium that are responsible for the effects on breast cancer cell lines for future drug development. Extension of this approach may help elucidate

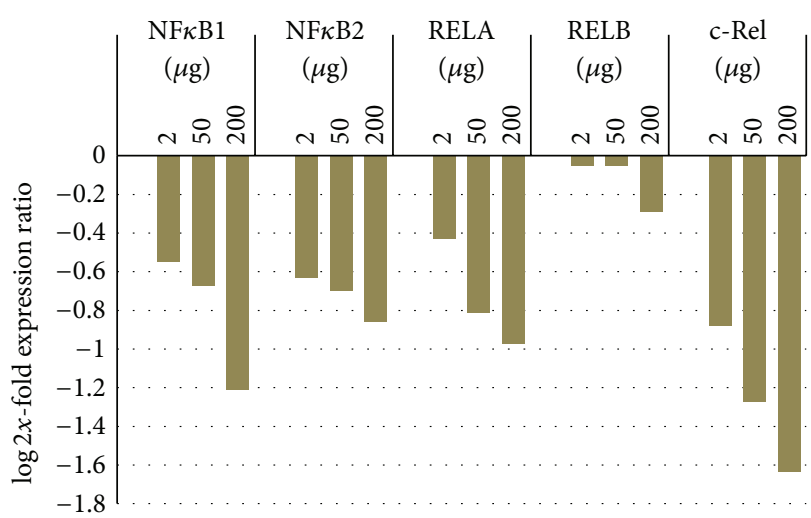

FIGURE 5: Changes in the expression levels of five NF- $\kappa$ B subunits, NFKB1 (nuclear factor kappa B1), NFKB2 (nuclear factor kappa B2), RELA ( $v$-rel avian reticuloendotheliosis viral oncogene homolog A), RELB (v-rel avian reticuloendotheliosis viral oncogene homolog B), and c-Rel (cellular counterpart of the v-Rel oncogene) in breast cancer MCF-7 cells treated with increasing concentrations $(2 \mu \mathrm{g}$, $50 \mu \mathrm{g}$, and $200 \mu \mathrm{g}$ ) of sponge extract compared to those of untreated cells.

the function of individual molecular species and prioritize them as drug targets.

\section{Conflict of Interests}

The authors declare that there is no conflict of interests regarding the publication of this paper.

\section{Authors' Contribution}

Susan Costantini and Giovanna Romano contributed equally to this work.

\section{Acknowledgments}

The authors thank the "Fishing Service of Stazione Zoologica Anton Dohrn" and "Parco Sommerso di Baia" in Naples for providing Geodia cydonium and Davide Caramiello of the Marine Resources for Research Service for his technical support in sponge maintenance.

\section{References}

[1] C. Porta, P. Larghi, M. Rimoldi et al., "Cellular and molecular pathways linking inflammation and cancer," Immunobiology, vol. 214, no. 9-10, pp. 761-777, 2009.

[2] S. Costantini, F. Capone, E. Guerriero, and G. Castello, "An approach for understanding the inflammation and cancer relationship," Immunology Letters, vol. 126, no. 1-2, pp. 91-92, 2009.

[3] P. Allavena, G. Germano, F. Marchesi, and A. Mantovani, "Chemokines in cancer related inflammation," Experimental Cell Research, vol. 317, no. 5, pp. 664-673, 2011.

[4] S. Costantini, G. Castello, and G. Colonna, "Human cytokinome: a new challenge for systems biology," Bioinformation, vol. 5, no. 4, pp. 166-167, 2010. 
[5] R. D. C. da Silveira E Sá, L. N. Andrade, R. D. R. B. de Oliveira, and D. P. de Sousa, "A review on anti-inflammatory activity of phenylpropanoids found in essential oils," Molecules, vol. 19, no. 2, pp. 1459-1480, 2014.

[6] F. Rusolo, B. Pucci, G. Colonna et al., "Evaluation of selenite effects on selenoproteins and cytokinome in human hepatoma cell lines," Molecules, vol. 18, no. 3, pp. 2549-2562, 2013.

[7] E. Guerriero, A. Sorice, F. Capone et al., "Effects of lipoic acid, caffeic acid and a synthesized lipoyl-caffeic conjugate on human hepatoma cell lines," Molecules, vol. 16, no. 8, pp. 6365-6377, 2011.

[8] S. Costantini, F. Rusolo, V. de Vito et al., "Potential antiinflammatory effects of the hydrophilic fraction of pomegranate (Punica granatum L.) seed oil on breast cancer cell lines," Molecules, vol. 19, no. 6, pp. 8644-8660, 2014.

[9] S. de Marino, C. Festa, F. Zollo et al., "Phytochemical profile of Juniperus oxycedrus ssp. oxycedrus berries: a new monoterpene glucoside and evaluation of the effects on cancer cell lines," Phytochemistry Letters, vol. 10, pp. 152-159, 2014.

[10] M. G. Haygood, E. W. Schmidt, S. K. Davidson, and D. J. Faulkner, "Microbial symbionts of marine invertebrates: opportunities for microbial biotechnology," Journal of Molecular Microbiology and Biotechnology, vol. 1, no. 1, pp. 33-43, 1999.

[11] M. H. R. Seleghim, S. P. Lira, M. H. Kossuga et al., "Antibiotic, cytotoxic and enzyme inhibitory activity of crude extracts from Brazilian marine invertebrates," Brazilian Journal of Pharmacognosy, vol. 17, no. 3, pp. 287-318, 2007.

[12] K. Senthilkumar and S.-K. Kim, "Marine invertebrates natural products for anti-inflammatory and chronic diseases," Evidence-Based Complementary and Alternative Medicine, vol. 2013, Article ID 572859, 10 pages, 2013.

[13] S. Perdicaris, T. Vlachogianni, and A. Valavanidis, "Bioactivenatural substances from marine sponges new developmentsand prospects for future pharmaceuticals," Natural Products Chemistry \& Research, vol. 1, no. 3, pp. 1-8, 2013.

[14] A. Dellai, M. Deghrigue, A. Laroche-Clary et al., "Evaluation of antiproliferative and anti-inflammatory activities of methanol extract and its fractions from the Mediterranean sponge," Cancer Cell International, vol. 12, article 18, 2012.

[15] L. G. Azevedo, G. G. Peraza, C. Lerner, A. Soares, N. Murcia, and A. L. Muccillo-Baisch, "Investigation of the anti-inflammatory and analgesic effects from an extract of Aplysina caissara, a marine sponge," Fundamental \& Clinical Pharmacology, vol. 22, no. 5, pp. 549-556, 2008.

[16] P. Proksch, R. A. Edrada, and R. Ebel, "Drugs from the seas-current status and microbiological implications," Applied Microbiology and Biotechnology, vol. 59, no. 2-3, pp. 125-134, 2002.

[17] L. T. Vahdat, B. Pruitt, C. J. Fabian et al., "Phase II study of eribulin mesylate, a halichondrin B analog, in patients with metastatic breast cancer previously treated with an anthracycline and a taxane," Journal of Clinical Oncology, vol. 27, no. 18, pp. 2954-2961, 2009.

[18] K. L. Rinehart, "Antitumor compounds from tunicates," Medicinal Research Reviews, vol. 20, no. 1, pp. 1-27, 2000.

[19] I. Posadas, M. C. Terencio, S. de Rosa, and M. Payá, “Cavernolide: a new inhibitor of human sPLA2 sharing unusual chemical features," Life Sciences, vol. 67, no. 24, pp. 3007-3014, 2000.

[20] D. L. Burgoyne, R. J. Andersen, and T. M. Allen, "Contignasterol, a highly oxygenated steroid with the 'unnatural' $14 \beta$ configuration from the marine sponge Petrosia contignata thiele, 1899," Journal of Organic Chemistry, vol. 57, no. 2, pp. 525528, 1992.

[21] F. D’Acquisto, V. Lanzotti, and R. Carnuccio, "Cyclolinteinone, a sesterterpene from sponge Cacospongia linteiformis, prevents inducible nitric oxide synthase and inducible cyclo-oxygenase protein expression by blocking nuclear factor- $\kappa \mathrm{B}$ activation in J774 macrophages," Biochemical Journal, vol. 346, no. 3, pp. 793798, 2000.

[22] M. M. El-Sayed, H. A. El-Nahas, E.-S. S. Adel-Hameed, and E. A. El-Wakil, "Investigation and antioxidant of phenolic compounds of the leaves of Gleditsia Triacanthos L.," International Journal of Pharmacy and Pharmaceutical Sciences, vol. 5, no. 2, pp. 172-177, 2013.

[23] D. G. Rothwell, Y. Li, M. Ayub et al., "Evaluation and validation of a robust single cell RNA-amplification protocol through transcriptional profiling of enriched lung cancer initiating cells," BMC Genomics, vol. 15, no. 1, article 1129, 2014.

[24] H. Mi, B. Lazareva-Ulitsky, R. Loo et al., "The PANTHER database of protein families, subfamilies, functions and pathways," Nucleic Acids Research, vol. 33, pp. D284-D288, 2005.

[25] M. W. Pfaffl, G. W. Horgan, and L. Dempfle, "Relative expression software tool (REST) for group-wise comparison and statistical analysis of relative expression results in real-time PCR," Nucleic Acids Research, vol. 30, no. 9, article e36, 2002.

[26] S. Costantini, G. di Bernardo, M. Cammarota, G. Castello, and G. Colonna, "Gene expression signature of human HepG2 cell line," Gene, vol. 518, no. 2, pp. 335-345, 2013.

[27] A. Zuppa, S. Costantini, and M. Costantini, "Comparative sequence analysis of bacterial symbionts from the marine sponges Geodia cydonium and Ircinia muscarum," Bioinformation, vol. 10, no. 4, pp. 196-200, 2014.

[28] I. D. B. Arthaud, F. A. R. Rodrigues, P. C. Jimenez et al., "Studies on the secondary metabolites of a Pseudoalteromonas sp. Isolated from sediments collected at the northeastern coast of Brazil," Chemistry and Biodiversity, vol. 9, no. 2, pp. 418-427, 2012.

[29] D. Ackermann, P. H. List, and H. G. Menssen, "Occurrence of a new purine base C6H7N5 in the giant siliceous sponge (Geodia gigas)," Hoppe-Seyler's Zeitschrift für physiologische Chemie, vol. 312, no. 4-6, pp. 210-213, 1958.

[30] A. Migliuolo, V. Piccialli, and D. Sica, "Steroidal ketones from the sponge Geodia cydonium," Journal of Natural Products, vol. 53, no. 5, pp. 1262-1266, 1990.

[31] G. R. Pettit, J. A. Rideout, and J. A. Hasler, "Isolation of geodiastatins 1 and 2 from the marine sponge Geodia mesotriaena," Journal of Natural Products, vol. 44, no. 5, pp. 588-592, 1981.

[32] M. Rangel, K. Konno, K. Brunaldi, J. Procopio, and J. C. De Freitas, "Neurotoxic activity induced by a haemolytic substance in the extract of the marine sponge Geodia corticostylifera," Comparative Biochemistry and Physiology-C Toxicology and Pharmacology, vol. 141, no. 2, pp. 207-215, 2005.

[33] M. Rangel, M. P. Prado, K. Konno, H. Naoki, J. C. Freitas, and G. M. Machado-Santelli, "Cytoskeleton alterations induced by Geodia corticostylifera depsipeptides in breast cancer cells," Peptides, vol. 27, no. 9, pp. 2047-2057, 2006.

[34] M. Rangel, M. Ionta, S. C. Pfister, R. Adolpho Sant’anna Ferreira, and G. Maria Machado-Santelli, "Marine sponge depsipeptide increases gap junction length in HTC cells transfected with Cx43-GFP," Cell Biology International Reports, vol. 17, no. 1, Article ID e00003, 2010.

[35] C. C. Bancroft, Z. Chen, G. Dong et al., "Coexpression of proangiogenic factors IL-8 and VEGF by human head and neck 
squamous cell carcinoma involves coactivation by MEK-MAPK and IKK-NF- $\kappa$ B signal pathways," Clinical Cancer Research, vol. 7, no. 2, pp. 435-442, 2001.

[36] R. Salcedo, M. L. Ponce, H. A. Young et al., "Human endothelial cells express CCR2 and respond to MCP-1: direct role of MCP-1 in angiogenesis and tumor progression," Blood, vol. 96, no. 1, pp. 34-40, 2000.

[37] I. Fabregat, "Dysregulation of apoptosis in hepatocellular carcinoma cells," World Journal of Gastroenterology, vol. 15, no. 5, pp. 513-520, 2009.

[38] S. J. Burke, M. R. Goff, D. Lu, D. Proud, M. D. Karlstad, and J. J. Collier, "Synergistic expression of the CXCL10 gene in response to IL- $1 \beta$ and IFN- $\gamma$ Involves NF- $\kappa$ B, phosphorylation of STAT1 at Tyr701, and acetylation of histones $\mathrm{H} 3$ and H4," Journal of Immunology, vol. 191, no. 1, pp. 323-336, 2013.

[39] A. Randazzo, G. Bifulco, C. Giannini et al., "Halipeptins A and B: two novel potent anti-inflammatory cyclic depsipeptides from the Vanuatu marine sponge Haliclona species," Journal of the American Chemical Society, vol. 123, no. 44, pp.10870-10876, 2001.

[40] J. Balsinde, M. A. Balboa, P. A. Insel, and E. A. Dennis, "Regulation and inhibition of phospholipase A2," Annual Review of Pharmacology and Toxicology, vol. 39, pp. 175-189, 1999.

[41] K. F. Lind, E. Hansen, B. Østerud et al., "Antioxidant and antiinflammatory activities of barettin," Marine Drugs, vol. 11, no. 7, pp. 2655-2666, 2013.

[42] K. Pfeifer, H. C. Schröder, B. Rinkevich et al., "Immunological and biological identification of tumour necrosis-like factor in sponges: endotoxin that mediates necrosis formation in xenografts," Cytokine, vol. 4, no. 2, pp. 161-169, 1992.

[43] X. Du, X.-Q. Li, L. Li, Y.-Y. Xu, and Y.-M. Feng, "The detection of ESR1/PGR/ERBB2 mRNA levels by RT-QPCR: a better approach for subtyping breast cancer and predicting prognosis," Breast Cancer Research and Treatment, vol. 138, no. 1, pp. 59-67, 2013.

[44] T. D. Gilmore, "Introduction to NF- $\kappa$ B: players, pathways, perspectives," Oncogene, vol. 25, no. 51, pp. 6680-6684, 2006.

[45] F. Rusolo, B. Pucci, G. Colonna et al., "Evaluation of selenite effects on selenoproteins and cytokinome in human hepatoma cell lines," Molecules, vol. 18, no. 3, pp. 2549-2562, 2013. 


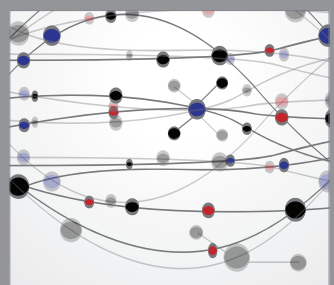

The Scientific World Journal
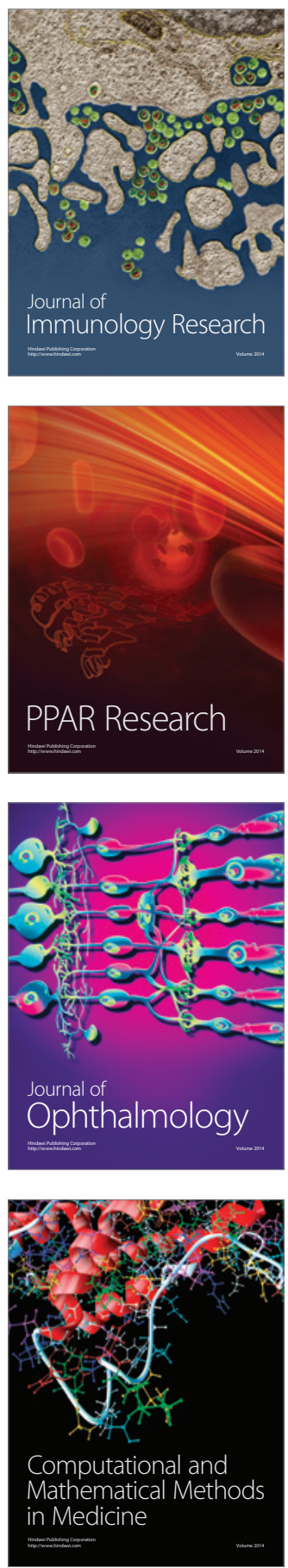

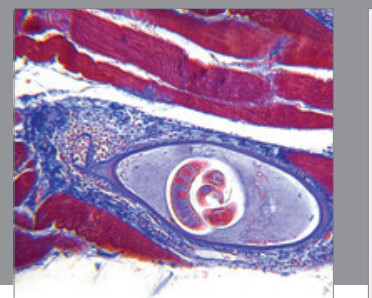

Gastroenterology

Research and Practice
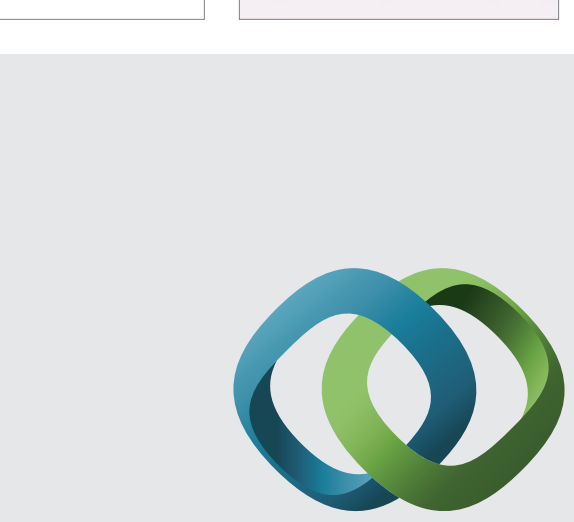

\section{Hindawi}

Submit your manuscripts at

http://www.hindawi.com
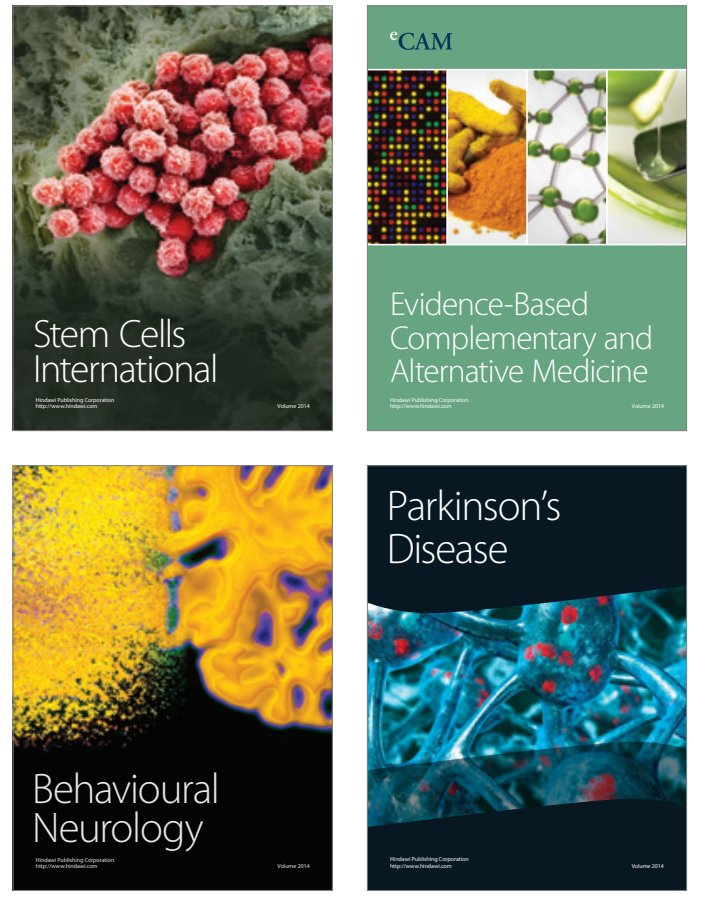
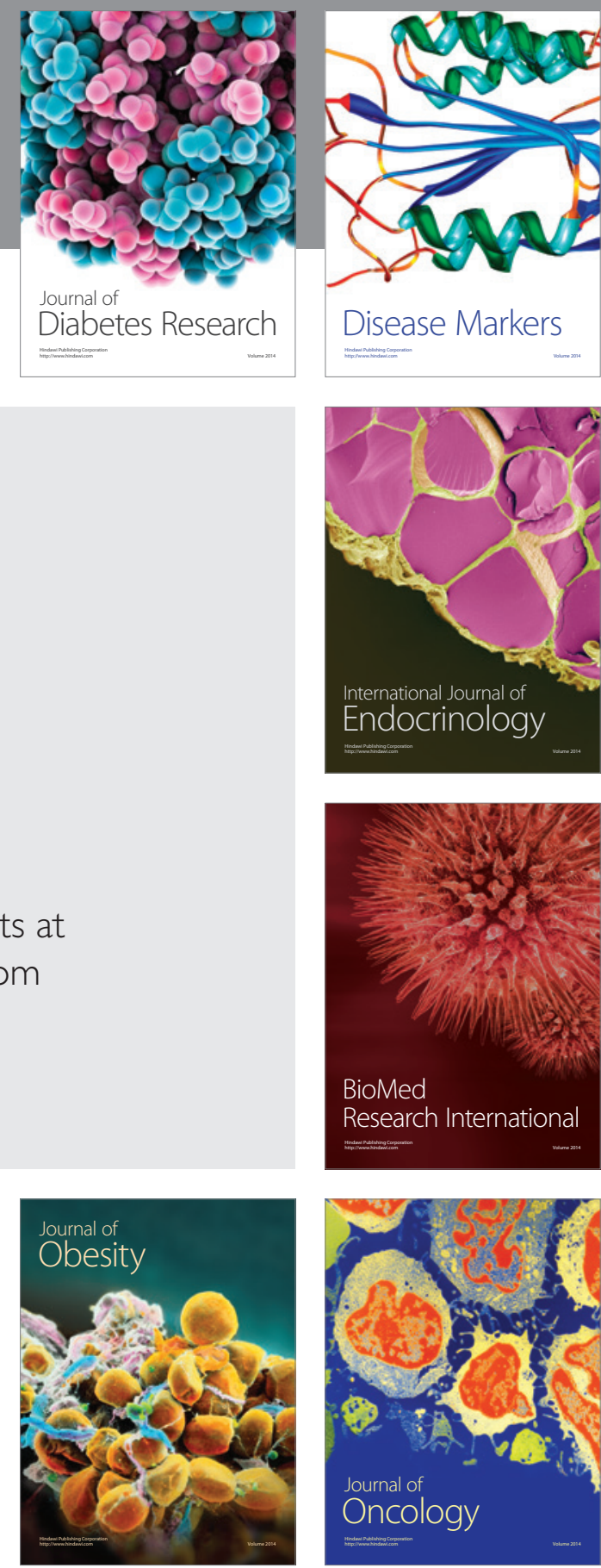

Disease Markers
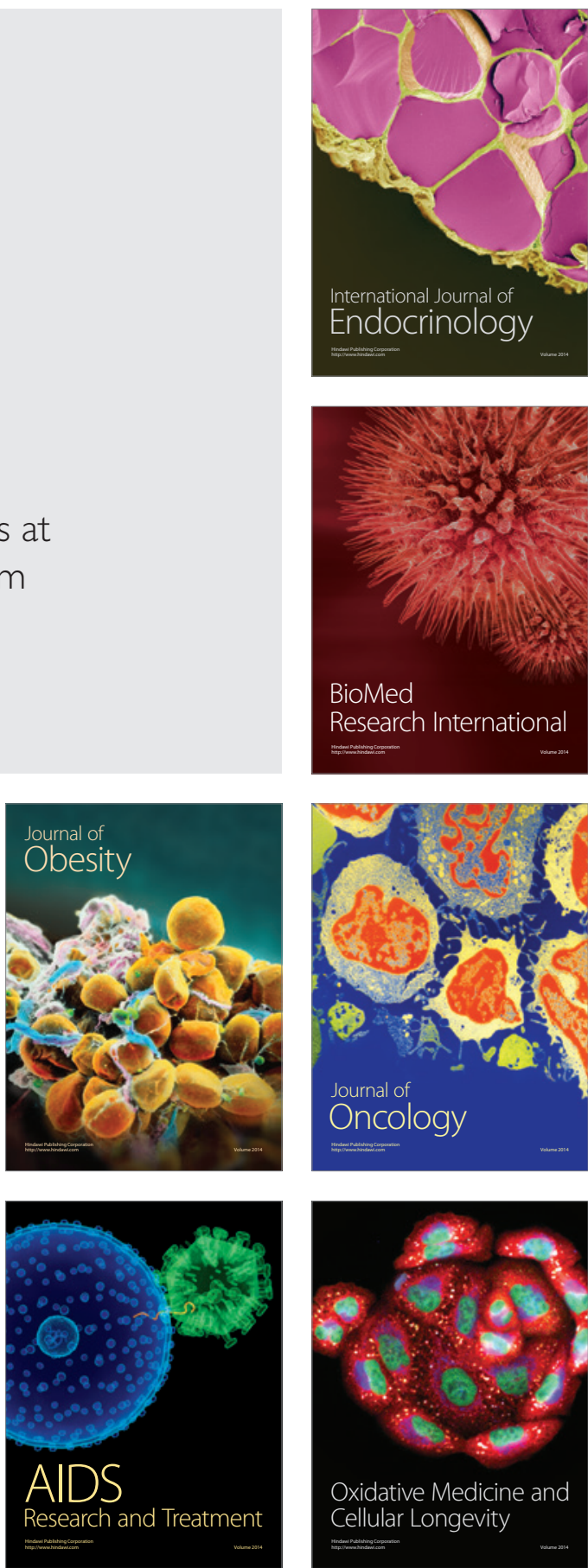